\title{
Integration of Women Veterans into VA Quality Improvement Research Efforts: What Researchers Need to Know
}

\author{
Elizabeth M. Yano, PhD, MSPH', ${ }^{1,}$, Patricia Hayes, $P h D^{3}$, Steven Wright, $P h D^{4}$, \\ Paula P. Schnurr, PhD ${ }^{5,6}$, Linda Lipson, MA7, Bevanne Bean-Mayberry, MD, MSHS ${ }^{1,8}$, \\ and Donna L. Washington, MD, MPH ${ }^{1,8}$
}

\begin{abstract}
'VA Greater Los Angeles HSR\&D Center of Excellence, Sepulveda, CA, USA; ${ }^{2}$ Department of Health Services, UCLA School of Public Health, Los Angeles, CA, USA; ${ }^{3}$ U.S. Department of Veterans Affairs, Women Veterans Health Strategic Health Care Group, Office of Public Health \& Environmental Hazards, Washington, DC, USA; ${ }^{4}$ Office of Quality \& Performance, Veterans Health Administration, Providence, RI, USA; ${ }^{5}$ White River Junction VA Medical Center, National Center for PTSD, White River Junction, VT, USA; ${ }^{6}$ Dartmouth Medical School, Hanover, NH, USA; ${ }^{7}$ VA HSR\&D Service, Office of Research \& Development, Veterans Health Administration, Washington, DC, USA; ${ }^{8}$ Department of Medicine, UCLA School of Medicine, Los Angeles, CA, USA.
\end{abstract}

The Department of Veterans Affairs (VA) and other federal agencies require funded researchers to include women in their studies. Historically, many researchers have indicated they will include women in proportion to their VA representation or pointed to their numerical minority as justification for exclusion. However, women's participation in the military-currently $14 \%$ of active military-is rapidly changing veteran demographics, with women among the fastest growing segments of new VA users. These changes will require researchers to meet the challenge of finding ways to adequately represent women veterans for meaningful analysis. We describe women veterans' health and health-care use, note how VA care is organized to meet their needs, report gender differences in quality, highlight national plans for women veterans' quality improvement, and discuss VA women's health research. We then discuss challenges and potential solutions for increasing representation of women veterans in VA research, including steps for implementation research.

KEY WORDS: quality improvement; disparities; implementation research; women's health; veterans.

Several VA Health Services Research and Development (HSR\&D) Service funded studies provided source information for this paper, including Impact of Practice Structure on the Quality of Care for Women Veterans (phase 1 project no. IIR-04-036 and phase 2 project no. IAE07-170), and the Women Veterans Ambulatory Care Use project phase II (project no. IAE-06-083). Dr. Yano's effort was funded by a VA HSR\&D Research Career Scientist Award (project no. 05-195), while Dr. Bean-Mayberry's effort was funded by a VA HSR\&D Career Development Transition Award (project no. RCD 02-039). We acknowledge the VA Office of Quality and Performance for direct contribution of results from internal reports on gender disparities in VA quality of care. The issues summarized in this paper were presented at the National VA Guality Enhancement Research Initiative (QUERI) Meeting, Phoenix, AZ, December 12, 2008, and the VA HSR\&D Meeting, Baltimore, MD, February 12, 2009.
J Gen Intern Med 25(Suppl 1):56-61

DOI: $10.1007 / \mathrm{s} 11606-009-1116-4$

(c) Society of General Internal Medicine 2009

\section{INTRODUCTION}

Ideally, research participants should represent the populations for whom the resulting treatments or care improvements will be implemented. For women, concerns about the harm that potential exposures could have on developing fetuses resulted in exclusions of women of childbearing age until the early 1990s, when federal agencies reversed their policies. ${ }^{1-3}$ Federal agencies now require their funded researchers to include women in their research in sufficient numbers to enable valid analyses of differences in intervention effects where pertinent. ${ }^{4}$ Cost cannot be used as justification for their exclusion, and programs for effective outreach to recruit women into studies are required.

Research within the Veterans Health Administration has similar requirements to include women veterans as subjects whenever appropriate. Historically, many researchers have either indicated they will include women in proportion to their representation in VA settings or justified the exclusion of women veterans based on their numerical minority. Among researchers who include women, many find general sampling strategies insufficient to enable subgroup analyses by gender. However, women's participation in the military-now $14 \%$ of active military-is rapidly changing veteran demographics. Women are among the fastest growing segments of new VA users. Changes in gender mix affect clinical care arrangements and the mix of services that many VA facilities provide, and further increase the imperative for researchers to identify strategies to ensure women veterans' representation in sufficient numbers to conduct meaningful analyses.

In this paper, we describe women veterans' use of health care, how VA care is currently organized, gender differences in quality, national plans for quality improvement, and advances in VA women's health research. We then discuss challenges and potential solutions for increasing the representation of women veterans in VA research, building on experiences from the VA's only cooperative trial among women veterans as well as other research. 


\section{Women Veterans: What Do We Know About Them?}

In 2008 , US women veterans numbered 1.8 million, accounting for $7.7 \%$ of the US veteran population. VA estimates indicate that women will comprise $10.0 \%$ of the veteran population by 2018 , and $14.3 \%$ by 2033 . Younger, on average, than male veterans (48 vs. 61 years), women veterans are less likely to use VA health care than male veterans (15\% versus $22 \%$ in 2007). However, VA enrollment has reached twice the national level (44.2\%) among women discharged from military service in Iraq and Afghanistan, and of those VA enrollees, $43.8 \%$ have already made two or more visits. Despite this shift, most of today's women veterans obtain all or most of their medical care outside the VA. ${ }^{5}$ Barriers to VA use include lack of information about VA eligibility, benefits, and available women's health-care services, and perceptions of poor VA quality. ${ }^{6-7}$

Among women veterans, VA users are more likely than VA nonusers to have low income, no medical insurance, poor health status and social support, and a military serviceconnected disability. ${ }^{6}$ Their mental health and chronic disease burdens are comparable to male VA users; top diagnoses include post-traumatic stress disorder (PTSD), hypertension, depression, hyperlipidemia, and chronic low back pain. ${ }^{8,9}$

\section{How is VA Women's Health Care Organized?}

As women veterans have entered the VA health-care system in increasing numbers, VA managers and providers have struggled with the challenge of organizing and delivering genderspecific and gender-sensitive services in a system historically focused on treating men. Currently, most women veterans who use VA receive care at 1 of about 200 VA medical centers and large community-based outpatient clinics. Nationally, these facilities have adopted one of four basic models for delivering primary care services to women: (1) a separate women's primary care (PC) clinic (39\%), (2) general PC clinics that preferentially assign women to designated providers (13\%), (3) a combination of (1) and (2), or (4) general PC clinics where care for women is fully integrated with that of men (20\%). ${ }^{10}$ Of the two-thirds that have a women's PC clinic (combining the $39 \%$ with and $28 \%$ without designated providers), $44 \%$ provide gender-specific exams only. In contrast, most women veterans obtain their mental health care in fully integrated clinics, with $34 \%$ using designated providers and a few VAs creating separate women's mental health clinics. Fewer than half of VAMCs have a gynecology clinic for provision of specialized women's health services (44\%). ${ }^{11}$

Gender-specific care (e.g., reproductive health services) and care for conditions of higher prevalence among women (e.g., osteoporosis) or with different clinical presentations (e.g., myocardial infarction) imposes considerable training and experiential requirements on a VA workforce with limited exposure to female patients. Researchers have described health-care staff's difficulty maintaining gender sensitivity, for example, presuming that women in VA settings are a spouse. ${ }^{12}$ Lack of privacy due to physical plant and procedural problems that result in women being denied access to needed specialized service remain longstanding concerns (e.g., need for separate inpatient rooms/wards for women). ${ }^{13,14}$ The high prevalence of military sexual trauma among women veterans also requires a substantial degree of staff and provider sensitivity, as well as accommodations in establishing safe and comfortable care environments. ${ }^{15}$ Understanding how VA care is organized for women is therefore important for researchers interested in engaging in women veterans' research.

\section{How Does Quality of Care Compare for Men and Women Veterans in the VA Health-Care System?}

The VA Office of Quality and Performance (OQP) nationally monitors prevention and chronic disease quality indicators based on nationally accepted guidelines through externally performed chart reviews of randomly selected patients at each VA. OQP oversamples women as part of this assessment, enabling direct comparisons by gender and providing useful guidance for areas warranting attention. In 2007, OQP oversampled approximately 12,000 outpatient women veterans, age 50-65, to examine age-stratified gender differences in quality.

Overall, quality of care for women veteran VA users is quite high and outperforms most HEDIS measures among commercial, Medicare, or Medicaid populations. ${ }^{16-19}$ However, significant and durable gaps in care exist when comparing quality by gender in VA outpatient settings, including general prevention measures (e.g., colorectal cancer screening, immunization status, and depression screening) and management of women veterans with cardiovascular risk [e.g., lower use of cholesterol medications and poorer low-density lipoprotein (LDL)-cholesterol control]. Among diabetics, women veterans are significantly less likely to have LDL cholesterols lower than 100 (or $<130$ ), testing for proteinuria, or timely retinal examinations. More research is needed to determine whether these differences reflect patient characteristics (e.g., medication adherence, differences in access/use), ${ }^{20}$ provider issues (e.g., proficiency, attitudes), or organizational factors (e.g., how local VA care for women is organized and coordinated). ${ }^{10,21}$

\section{Women Veterans Health Strategic Health-Care Group (WVHSHG)}

In recognition of the growth of women veterans using VA care, as well as their unique health-care needs, VA elevated oversight of women's health care by creating the WVHSHG in 2007. The WVHSHG provides strategic direction and programmatic support to address the health care needs of women veterans and works to ensure that timely, equitable, highquality comprehensive health-care services are provided in a sensitive and safe environment at VA health facilities nationwide. The VA also mandated that all VA facilities have a fulltime Women Veterans Program Manager (WVPM). The WVHSHG and WVPMs provide built-in partnerships for implementation research that may directly inform policy and practice initiatives (Table 1).

\section{VA Women's Health Research}

In view of the military's changing demographics and anticipated impacts on the VA patient population, the VA Office of Research and Development sponsored development of the first-ever VA women's health research agenda in $2004 .{ }^{9}$ The agenda was the product of a national consensus development conference attended by representatives from the VA, academia, and other federal agencies (e.g., NIH, AHRQ). ${ }^{22}$ Conferees 


\section{Table 1. Women Veterans Health Strategic Health-Care Group Priorities: Building a Quality Improvement Research Agenda for Women}

\section{Strategic priorities \\ Redesign primary care delivery for women veterans}

to integrate gender-specific services

Accurately represent and evaluate women veterans' health and health-care needs through data and analysis

Post-deployment health and readjustment issues among women veterans

Implement risk reduction strategies in prescribing medications
Quality Improvement research opportunities

- Evaluate variations in care

- Evaluate quality of care delivered under different care models

- Develop and test new care models

- Develop and test provider education interventions to advance their interest and proficiency in women's health

- Develop and evaluate computerized decision support interventions to support

integration of gender-specific care in routine primary care visits

- Develop and evaluate patient navigation and/or care management interventions to support coordination across VA providers, between $\mathrm{VA} /$ contract providers

- Evaluate determinants of gender disparities in quality (e.g., patient, provider, organizational, area)

- Identify predictors of quality in high vs. low performing VA networks and/or facilities (outliers)

- Collect new primary data needed to characterize health or health care needs not already captured by administrative or performance data (e.g., gender-sensitive patient satisfaction)

- Develop and evaluate new gender-specific performance measures (e.g., follow-up of abnormal Pap smears)

- Adapt and evaluate "best practice" interventions and other innovations from private or other public sectors for use in VA

- Adapt interventions found to be effective among male veterans for use among women veterans (e.g., in different clinic venues, with adapted study materials, on related conditions)

- Assess health and health care needs among returning women veterans

- Evaluate determinants of post-deployment high utilization among women veterans

- Evaluate patterns of injury and illness, including possible exposures to toxic substances, animal exposures, evaluation for depleted uranium exposure from munitions and shielding

- Evaluate quality of care for menstrual disorders, contraceptive management (consequences of continuous use), pregnancy, infertility, urinary tract infections (anecdotal reports of high rates)

- Evaluate quality of care coordination for comorbid physical and mental health conditions

- Evaluate transitions from active duty/guard/reserve to home (including role impacts for mothers, such as attachment disruption and parenting issues, and as civilian employees)

- Develop and test quality improvement interventions based on identified quality gaps

- Evaluate patterns of medication use among women veterans (including access/use of medications with teratogenic properties as well as informed consent)

- Evaluate access to contraception when appropriate

- Develop and test interventions for reducing risk of medication prescribing (errors, dosage problems, contraindications, adverse events) reviewed the VA's research portfolio, data on the prevalence of women veterans' health conditions, results of a systematic review of the published literature, and barriers to conducting research on women veterans. ${ }^{9,23,24}$ In parallel, the VA Cooperative Studies Program funded the first multi-site trial of treatment for PTSD among women veterans. ${ }^{25}$

The VA has also identified research priorities for women's health, represented by special research solicitations. ${ }^{26}$ High priority topics include assessments of quality, costs, access, continuity, and coordination of care for women with different health conditions (e.g., mental health, gender-specific services), for different subpopulations (e.g., by era of service), across the spectrum of care (e.g., preventive, chronic, acute, rehabilitative, long-term, and end-of-life care). ${ }^{26}$ The VA also maintains interest in innovative models of care that facilitate coordination across providers/settings, or otherwise reduce gender-related gaps in care.

As a result, the VA's portfolio has significantly expanded over the past 5 years (Table 2). These studies include research focused exclusively on women as well as projects that have made special efforts to augment samples with women veterans to better understand, for example, gender differences in post-deployment re-integration. Current research examines the complex interactions of physical and mental health, unique risks and outcomes of military service, barriers to care, and patterns of access and utilization. Reflecting the infusion of returning women veterans, research is also directed at analyzing the needs and experiences of the new generation of women from Operation Enduring Freedom and Operation Iraqi Freedom, including women who served in the National Guard and Reserves.

VA's future research agenda will be guided by results from the growing body of work already underway, in addition to results of the recently completed National Survey of Women Veterans and an updated evidence synthesis that will capture the surge in relevant published literature in the past 5 years (both due out in late 2009). These will provide a strong knowledge base regarding women veterans' health-care needs, access, and utilization, as well as gaps in care. However, we believe there is an urgent need for intervention research, to rapidly translate this base into pilot and larger scale intervention studies. Priorities should include 
Table 2. Current VA Women's Health Services Research Portfolio (Through FY08)*

\begin{tabular}{|c|c|}
\hline General topic & Funded research studies \\
\hline Health-care needs, utilization, outcomes, and quality & $\begin{array}{l}\text { - Chronic physical and mental illness care in women veterans } \\
\text { - Assessment of preventive and chronic disease measures in women veterans } \\
\text { - Women veterans' ambulatory care use project } \\
\text { - Improving VA access and quality of care for women } \\
\text { - Alcohol misuse and the risk of post-surgical complication and mortality } \\
\text { - The quality of locoregional breast cancer treatment for breast cancer in VA } \\
\text { - Study of women veterans in menopause }\end{array}$ \\
\hline Organization of health services to women veterans & $\begin{array}{l}\text { - Impact of practice structure on quality of care for women veterans } \\
\text { - Implementation and sustainability of VA women's mental health clinics }\end{array}$ \\
\hline $\begin{array}{l}\text { Sexual trauma, military sexual trauma (MST), } \\
\text { intimate partner violence }\end{array}$ & $\begin{array}{l}\text { - Sexual violence and women veterans gynecological health } \\
\text { - Physical and sexual assault in deployed women: risks, outcomes and services } \\
\text { - Evaluation of military sexual trauma screening and treatment } \\
\text { - Longitudinal study of MST effects on PTSD and health behavior among women Marines } \\
\text { - Detection of intimate partner violence: Implications for intervention } \\
\text { - Combat, sexual assault, and PTSD in OEF/OIF military women }\end{array}$ \\
\hline Posttraumatic stress disorder (PTSD) & $\begin{array}{l}\text { - Gender and medical needs of OEF/OIF veterans with PTSD and comorbid substance abuse } \\
\text { - Examining the diagnostic and clinical utility of the PTSD checklist } \\
\text { - Barriers and facilitators to PTSD treatment seeking } \\
\text { - Re-engineering systems for the primary care treatment of PTSD } \\
\text { - Pilot study of PTSD-focused cognitive behavioral therapy for partner violence }\end{array}$ \\
\hline Post-deployment health and other related research & $\begin{array}{l}\text { - Women veterans cohort study } \\
\text { - Further development and validation of the DRRI } \\
\text { - Predicting post-deployment mental health, substance abuse, and service needs } \\
\text { - Community re-integration and service needs for women veteran mothers }\end{array}$ \\
\hline
\end{tabular}

*This portfolio represents studies funded by VA HSR\&D Service. Other VA Office of Research \&. Development Services and the Department of Defense also fund research relevant to women veterans that are not captured by this portfolio review. ${ }^{38-39}$

OEF/OIF refers to Operation Enduring Freedom and Operation Iraqi Freedom

interventions to improve (1) knowledge, awareness, and access to VA care, (2) quality of women's health care (both gender-neutral and gender-specific), and (3) health professionals' women's health proficiency (both clinical knowledge of women's health and gender sensitivity). In the VA Quality Enhancement Research Initiative (QUERI) framework, VA women's health research sits at steps 2 (identify best practices) and 3 (define existing practice patterns and outcomes across the VA and current variation from best practices). ${ }^{27}$ Moving to step 4 (identify and implement interventions to promote best practices) should be at the forefront of future initiatives. The systematic approach to developing VA's women's health research agenda combined with the QUERI framework provides a model for research development for other under-represented groups or topics.

\section{Challenges and Potential Solutions to Including Women Veterans in VA Research}

Many challenges remain to including women in VA research. Historically, researchers have been hampered because there were too few women veterans at most VA locations to effectively integrate them into single-site studies. Small sample sizes result in having not enough cases to analyze findings by gender subgroups, which in turn wastes the data that are collected. There are currently no explicit incentives to oversample women veterans, though VA principal investigators may apply for supplemental funding through standard project modification procedures to add women or increase their women veteran sample. The VA lacks an infrastructure to facilitate oversampling. Development of a women veterans' practice-based research network offers one potential model for remedying this barrier, which would accelerate testing of gender-specific interventions and inclusion of women in relevant studies currently limited to men. ${ }^{28-29}$
Women veterans can also be difficult to recruit given that they differ from non-VA users and men in their utilization patterns, and that VA care for women is organized differently at individual facilities (i.e., preferential assignment to and concentration within a women's clinic or dispersed across PC teams). Even among VAs with women's clinics, some function as comprehensive primary care centers, while others deliver only gender-specific exams. Recruitment must therefore be context-specific, requiring an understanding of variations in local clinic structure and patterns of care. For example, primary care-based interventions may be adapted to women's PC clinics by shifting to a different venue within the same facility, while other interventions may need to be modified to address additional gender-sensitive concerns (e.g., use of same-gender interviewers or providers).

Working with facilities that have established women's health programs offers another approach to facilitating inclusion of women in research. Identifying an interested local site principal investigator may be easier in such facilities, and they may have established communication networks allowing researchers to capitalize on the strength of their local clinical programs for women. Women Veterans Program Managers familiar with the women veterans served at each facility offer additional research-clinical partnership opportunities. The VA Office of Academic Affiliations also funds Women's Health Fellowship sites, while the WVHSHG awards VA Women's Health Clinical Centers of Excellence, all of which extend the network of likely partners for implementation research, in addition to the growing consortium of VA- and university-based women's health researchers. However, some providers may be unwilling to participate in research because of high caseloads. While clinicians working with men may face similar time pressures, our anecdotal experience suggests that pressures are greater for clinicians who focus their practice on women, perhaps due 
to more limited clinical backup and administrative support in women's programs. Protocols should take this into account by offsetting the burden of participation through, for example, offering free training, helping staff acquire new skills, and providing supervision to facilitate implementation.

Women-specific programs are also undergoing changes, with the dissolution of some programs in favor of integrated clinics. Such changes can have negative consequences for study recruitment and ongoing implementation studies that have capitalized on the concentrated volume of women veterans in women's clinics to accomplish the goals of balanced recruitment.

Women veterans' younger age distribution may present barriers to research participation during usual VA hours of business due to work and/or childcare obligations. Few facilities can readily accommodate alternate hours of participation, which may bias sample enrollment. Provision of childcare also runs counter to the liability policies of many VA facilities, so in the absence of onsite childcare programs, there would be no place for the children of prospective research participants. It also remains unclear whether research resources may be used to pay for childcare. An alternative would be to provide adequate cash incentives to help offset participants' costs of a babysitter or other childcare arrangement for the period of their participation.

Assuring inclusion of women has specific implications for implementation research that aims to target an entire population or practice. Where women (or other under-represented groups) obtain care outside of traditional clinics/programs, it may be harder to identify and include them. Several steps are key to addressing this issue. First, it is essential to appraise the samples from which the evidence base was drawn (i.e., evidence of effectiveness by gender), an important step in any implementation study. Second, researchers should examine the distribution of patients in target practices to better understand how well the evidence relates to the planned implementation environment. Evaluating local patterns of care for different sociodemographic or other under-represented groups will help researchers better design, conduct, and analyze the results of their implementation studies. ${ }^{30}$

\section{DISCUSSION}

Over 25 years have passed since the VA required inclusion of women veterans in VA research, but regulations do not stipulate that women are to be included in sufficient numbers to enable subgroup analyses by gender. However, including women without ensuring meaningful ways to use their data wastes research resources. This "efficiency" argument has preserved the status quo. We argue that we now face a tipping point. Increased participation of women in the military is transforming the demographics of veterans enrolling in VA care, while the VA has already proactively identified gender disparities in chronic disease care and preventive practices among existing patients. These documented quality gaps, in addition to gender-specific and strategic concerns that are not represented by VA performance measures, reflect substantial opportunities for research. These areas also align with priorities outside the VA, offering the promise of collaborative research and use of VA findings to inform changes in other health-care settings. ${ }^{31,32}$

The VA's ability to contribute to advances in women's health research and to improved inclusion of women in non-genderspecific research is substantial. The VA health-care system has become a model for health-care reform, having long ago established high-quality electronic medical records with extensive decision support capabilities in the context of integrated service networks and continual performance monitoring and feedback. ${ }^{33-34}$ These capabilities increase the VA's ability to empirically examine gender differences, to evaluate realtime clinical decision support tools, and to use system-level policies and practice initiatives to improve quality of care. Capitalizing on the VA system's capabilities in the context of research on the impact of practice structure on the quality of care for women veterans, the WVHSHG has launched an ambitious national implementation plan for comprehensive practice redesign to enhance primary care delivery for women. This plan, the Women's Comprehensive Healthcare Implementation Plan (W-CHIP), is central to the future delivery of healthcare services to women veterans and will have a substantial impact on existing and future research.

We recommend that funders offer incentives to add women to existing projects and incorporate them in the design of new projects, always in sufficient numbers to conduct meaningful subgroup analyses. We also recommend ongoing funding of gender-specific research to ensure that VA equitably delivers high-quality care to all eligible veterans, meeting the needs of women as they consider whether the VA can be their "provider of choice." Adding women to an appropriate subset of VA's substantial research portfolio will increase their scientific yield, extending our knowledge of variations in care and intervention effectiveness by gender. ${ }^{36-37}$

Fortunately, many pathways exist to building a more balanced research portfolio, especially through research-clinical partnerships. The WVHSHG has brought new visibility and vigor to the systematic appraisal of women veterans' health-care needs, development and refinement of quality improvement (QI) initiatives, and evidence-based policy action. OQP now provides facility- and network-level feedback on performance by gender, informing managers of areas warranting action. Researchers have unprecedented opportunities to contribute to the nation's QI agenda for women's health in general and for women veterans specifically.

Acknowledgments: The issues summarized in this paper were presented at the National VA Quality Enhancement Research Initiative (QUERI) Meeting, Phoenix, AZ, December 12, 2008, and at the VA Health Services Research \& Development (HSR\&D) Meeting, Baltimore, $M D$, February 12, 2009. Studies contributing source information were funded by VA HSR\&D Service, including Impact of Practice Structure on the Quality of Care for Women Veterans (phase 1 project no. IIR-04-036 and phase 2 project no. IAE-07-170), and the Women Veterans Ambulatory Care Use project phase II (project no. IAE-06-083). Dr. Yano's effort on this work was funded by a VA HSR\&D Research Career Scientist (RCS) Award (project no. 05-195), while Dr. BeanMayberry's effort was funded by a VA HSR\&D Career Development Transition Award (CDTA) (project no. RCD 02-039). We also acknowledge the VA Office of Quality and Performance (OQP) for direct contribution of results from internal reports on gender disparities in VA quality of care. We thank Shirley Meehan, PhD, MBA, VA HSR\&D Service, for her institutional memory.

In addition to several co-authors (EMY, PPS, BBM, DLW), we would like to acknowledge the contributions of the many VA-based principal investigators who are actively engaged in the VA HSR\&Dfunded women veterans' research cited in Table 3, including Ranjana Banerjea, PhD; Katherine Bradley, MD; Cynthia Brandt, $\mathrm{PhD}$; Susan Eisen, PhD; April Gerlock, PhD; Rachel Kimerling, $\mathrm{PhD}$; Sarah Krein, PhD, RN; Gudrun Lange, PhD; Steven Luther, $\mathrm{PhD}$; Anne Sadler, PhD, RN; Nina Sayer, $\mathrm{PhD}$; Jillian Shipherd, 
PhD; Casey Taft, PhD; and Dawne Vogt, PhD. This work would not have been possible without the support of the VA Greater Los Angeles HSR\&D Center of Excellence (project no. 94-028), including Ismelda Canelo, MPA, and Danielle Rose, $\mathrm{PhD}$.

Conflict of interest: All of the coauthors are employees of the US Department of Veterans Affairs. Drs. Yano, Bean-Mayberry, Schnurr, and Washington have received VA research grant funding. None of the coauthors have specific conflicts of interest related to the manuscript.

Corresponding Author: Elizabeth M. Yano, $\mathrm{PhD}, \mathrm{MSPH}$; VA Greater Los Angeles HSR\&D Center of Excellence, Mailcode 152, 16111 Plummer Street, Sepulveda, CA 91343, USA (e-mail: Elizabeth yano@va.gov).

\section{REFERENCES}

1. Yang Y, Carlin AS, Faustino PJ, et al. Participation of women in clinical trials for new drugs approved by the Food and Drug Administration in 2000-2002. J Womens Health. 2009;18(3):303-10.

2. Brown BA, Long HL, Gould H, Weitz T, Milliken N. A conceptual model for the recruitment of diverse women into research studies. J Womens Health. 2000;9(6):625-32.

3. Wood SF. Tracking inclusion of women in clinical studies. J Womens Health. 2009;18(3):301-2.

4. Gilliss CL, Lee KA, Gutierrez Y, et al. Recruitment and retention of healthy minority women into community-based longitudinal research. J Womens Health Gend Based Med. 2001;10(1):77-85.

5. Murdoch M, Bradley A, Mather SH, Klein RE, Turner CL, Yano EM Women and war: What physicians should know. J Gen Intern Med. 2006;21(Suppl 3):S5-10.

6. Washington DL, Yano EM, Simon B, Sun S. To use or not to use: What influences why women veterans choose VA healthcare? J Gen Intern Med. 2006;21(Suppl 3):S11-18.

7. Washington DL, Kleimann S, Michelini AN, Kleimann KM, Canning M. Women veterans' perceptions and decision-making about VA health care. Mil Med. 2007;172(8):812-17.

8. Frayne SM, Parker VA, Christiansen CL, et al. Health status among 28,000 women veterans: The VA Women's Health Program Evaluation Project. J Gen Intern Med. 2006;21(Suppl 3):S40-6.

9. Yano EM, Bastian LA, Frayne SM, et al. Toward a VA women's health research agenda: Setting evidence-based priorities to improve the health and health care of women veterans. J Gen Intern Med. 2006;2 1(Suppl 3):S93-101.

10. Yano EM, Washington DL, Bean-Mayberry B. Impact of Practice Structure on the Quality of Care for Women Veterans (Final Report). Sepulveda, CA: VA HSR\&D Center of Excellence for the Study of Healthcare Provider Behavior; 2008.

11. Seelig MD, Yano EM, Bean-Mayberry B, Lanto AB, Washington DL. Availability of gynecologic services in the Department of Veterans Affairs. Womens Health Issues. 2008;18(3):167-73.

12. Vogt DS, Barry AA, King LA. Toward gender-aware health care: evaluation of an intervention to enhance care for female patients in the VA setting. J Health Psychol. 2008;13(5):624-38.

13. U.S. Government Accounting Office. Actions needed to insure that female veterans have equal access to VA benefits (GAO/HRD-82-98), 1982.

14. U.S. Government Accounting Office. VA health care for women: despite progress, improvements needed (GAO/HRD-92-23), 1992.

15. Kimerling R, Street AE, Gima K, Smith MW. Evaluation of universal screening for military-related sexual trauma. Psychiatr Serv. 2008;59 (6):635-40

16. U.S. Department of Veterans Affairs, Veterans Health Administration. Report to the Appropriations Committee of the U.S. House of Representatives in response to House Appropriations Report No. 110-186, accompanying Public Law 110-161, The Consolidated Appropriations Act, 2008 .
17. Chou AF, Brown AF, Jensen RE, Shih S, Pawlson G, Scholle SH. Gender and racial disparities in the management of diabetes mellitus among Medicare patients. Womens Health Issues. 2007;17(3):150-61.

18. Chou AF, Scholle SH, Weisman CS, Bierman AS, Correa-de-Araujo R, Mosca L. Gender disparities in the quality of cardiovascular disease care in private managed care plans. Womens Health Issues. 2007;17(3): 120-30.

19. Bird CE, Fremont AM, Bierman AS, et al. Does quality of care for cardiovascular disease and diabetes differ by gender for enrollees in managed care plans? Women's Health Issues. 2007;17:131-8.

20. Bean-Mayberry B, Yano EM, Mor MK, Bayliss NK, Xu X, Fine MJ. Does sex influence immunization status for influenza and pneumonia in older veterans? J Am Geriatrics Soc. 2009;57(8):1427-32.

21. Wright SM, Lucartoto MA, Hayes PM, Yano EM. An analysis of the quality of care provided to men and women in the VA health care system. Washington DC: VA Office of Quality \& Performance (OQP) White Paper to the U.S. Assistant Deputy Under Secretary for Quality \& Patient Safety, Veterans Health Administration; 2008.

22. VA Women's Health Research Agenda-Setting Conference. Available at: http://www.research.va.gov/programs/womens_health/conference/ default.cfm, Accessed August 26, 2009.

23. Goldzweig CL, Balekian TM, Rolón C, Yano EM, Shekelle PG. The state of women veterans' health research: Results of a systematic literature review. J Gen Intern Med. 2006;21(Suppl 3):S82-92.

24. Frayne SM, Yu W, Yano EM, et al. Gender and use of care: Planning for tomorrow's Veterans Health Administration. J Womens Health. 2007;16 (8): 1188-99.

25. Schnurr PP, Friedman MJ, Engel CC, et al. Cognitive behavioral therapy for posttraumatic stress disorder in women: a randomized controlled trial. JAMA. 2007;297(8):820-30.

26. Veterans Health Administration. Program Announcement. HSR\&D Priorities for Investigator-Initiated Research (effective July 25, 2008). Accessed at http://www.research.va.gov/funding/solicitations/docs/ HSRD-IIR-Priorities-2008-09.pdf, July 22, 2009.

27. Stetler CB, McQueen L, Demakis J, Mittman BS. An organizational framework and strategic implementation for system-level change to enhance research-based practice: QUERI series. Implement Sci. 2008;3:30.

28. Nutting PA, Beasley JW, Werner JJ. Practice-based research networks answer primary care questions. JAMA. 1999;281:686-8.

29. Wasson JH, Jette AM, Johnson DJ, et al. A replicable and customizable approach to improve ambulatory care and research. J Ambul Care Manage. 1997;20(1):17-27.

30. Kochevar L, Yano EM. Understanding organizational needs and context: Beyond performance gaps. J Gen Intern Med. 2006;21(Suppl 2):S25-9.

31. Kasper AS. Health care reform and women's interests: Present, past and future. Womens Health Issues. 2004;14(4):107-11.

32. Correa-de-Araujo R. Serious gaps: How the lack of sex/gender-based research impairs health. J Womens Health. 2006;15(10):1116-22.

33. Yano EM, Simon BF, Lanto AB, Rubenstein LV. The evolution of changes in primary care delivery underlying the Veterans Health Administration's quality transformation. Am J Public Health. 2007;97 (12):2151-9.

34. Jha AK, Perlin JB, Kizer KW, Dudley RA. Effect of the transformation of the Veterans Affairs health care system on the quality of care. N Engl J Med. 2003;348(22):2218-27.

35. Evans DC, Nichol WP, Perlin JB. Effect of the implementation of an enterprise-wide electronic health record on productivity in the Veterans Health Administration. Health Econ Pol Law. 2006;(1Pt 2):163-9.

36. Bierman AS. Climbing out of our boxes: Advancing women's health for the twenty-first century. Womens Health Issues. 2003;13(6):201-3.

37. Pinn Vw. Sex and gender factors in medical studies: Implications for health and clinical practice. JAMA. 2003;289(4):397-400.

38. Perlin JB, Mather SH, Turner CL. Women in the military: New perspectives, new science. J Womens Health. 2005;14(9):861-2.

39. Friedl KE. Biomedical research on health and performance of military women: Accomplishments of the Defense Women's Health Research Program (DWHRP). J Womens Health. 2005; 14(9):764-802. 